\title{
Is what is visually believable necessarily true? The case of JACHALAY an "informative" film
}

\author{
Eleni Mouri \\ Assistant professor of animation, Graphic design department \\ TEl of Athens, Greece \\ mourye@teiath.gr
}

\begin{abstract}
Who are JACHALAY? Who could refer to and discuss about the Jachalay with certainty? Probably no one. They have been there, just over the centuries. We could only estimate and guess, since there is no communication at all".

"Jachalay" film (2012), is the thesis film of students Manos Gerogiannis and Giannis Zoumakis for the Graphic Design department of TEl of Athens.

The film's main idea is: Can somebody narrate the most blatant lies in a believable way?

Francis Vanoye's believed that in the development of narrative in literature and cinema, the signifier is developed in the form of expressive material and expressive form, while the signified in the conceptual material and conceptual the form.

So the following question appears: Which expressive form will be used in the signifier, to make the signified as much as possible believable?

At the same time the informative animation is the main instrument to visualize complex information, fast and clear, because the dramatic elements used in inform animation, aim to explain and inform. Inform animation uses info graphics in motion that means moving optical information representations of elements and knowledge; aiming at the fast, clear and direct communication. This communication uses visualized symbols and the viewer decodes them automatic.

In this context, we analyze the particular film by using it as a case study of how one could narrate the most absurd lies in the most believable way using infographics and animation language

Mainly, through this case study, we deal with the following questions:

- When we use fake information or plausibility half-truths, it is possible this audiovisual material to contain propaganda?

- How easy is through the artificial image, which is so easily created today, to become the recipients of misinformation?
\end{abstract}

Key Words: animation, info-graphics, informative animation, signifier, signified, propaganda, misinformation, verisimilitude 


\section{Introduction}

Arts evolution is parallel to the involvement of companies in the artistic institutions and their cohabitation with the mass culture. Company sponsorships of great artistic events or organizations cultural production aid this reconciliation. Therefore, the artist has been transformed from an activist who impeaches into a celebrity. The result of that is a general spiritual guidance of political aims: what Gramsci called hegemony.

Antonio Gramsci believes that hegemony as means of spiritual guidance or leadership in the cultural and social aspect of society. He explain that, for a particular group or class, in order to secure hegemony, it would not be necessary for them to take control of the state coercive mechanism. They would have to claim the "cultural domination", meaning the mind of the people. They would have to impose and redefine "common sense" according to their goals. This way, they could found general consent without securing the voluntary consent by supporting the state repressive mechanism. [1]

\section{Animation as a cultural product}

Nowadays, art is embraced by technology, assisting in the mass production of art. The same happened with anti-culture - the art of activists who oppose to the hegemony of the neo-liberal culture - which has been respectively helped by technology. Narrative animation has connected filming with painting and sculpture, and photography with graphic design. I has influenced as well the presence of nonreal narration in cinema. Gradually, this mix is established as a rule, which leads to the creation of a new narrative model.

By the other hand information is more direct when it is expressed through symbols. The result is the rapid visualisation of complex and clear information. The goal is to enrich the viewer's knowledge regarding a particular subject, an opinion and transmitting messages by guiding the audience towards an aim. Narrative information is being used on the signifier, while the signified is known-scientific material.

The structure of inform animation can be developed in three levels, depending on the desired target group; the visual attraction of the viewer, the understanding of the information and the maintenance of the transmitted knowledge through time.

\section{The case study movie}

The central idea of "Jachalay" movie [2] sets the following question: Could a signified become believable, if the signifier is truthful? The signifier is expressed through 
animation and infographics for maximum conveyance of reality. However, the signified is a lie.

The narrative form of the movie, the signifier, follows the linear narration of a documentary, meaning a non-dramatized narration. Documentary is a cinematographic type which describes reality. Therefore this non-dramatized narration distances the viewers who therefore accept that what they see as a description of reality. "Jachalay" contains interview shots [3] - however, everything the interviewees say are lies -, animation and digitally manipulated historical photographs. "Jachalay" uses as well infographics, of fake medical representations, in order to convince the audience of the presence of medical research. So, the signifier (form) becomes beautiful and truthful while the signified (content) are constructed lies. Narrator's language in most shots of the film, is English, which offers an extra layer of validity for Greek audience. Greek subtitles are used when necessary.

\section{Conceptual and cinematic analysis of the film}

The movie begins with eight shots of the first scene. All shots are from medium close until extreme close up. The camera is always eye-levelled for directness.

The focus is on one middle aged "actor", in his office, in front of several bookshelves, who says that he saw certain creatures called "Jachalay" but they did not affect his life. The actor's figure refers to the average literate European, therefore somebody who cannot be easily convinced by the any phenomenon. He speaks in English, placing the narration in northern Europe.

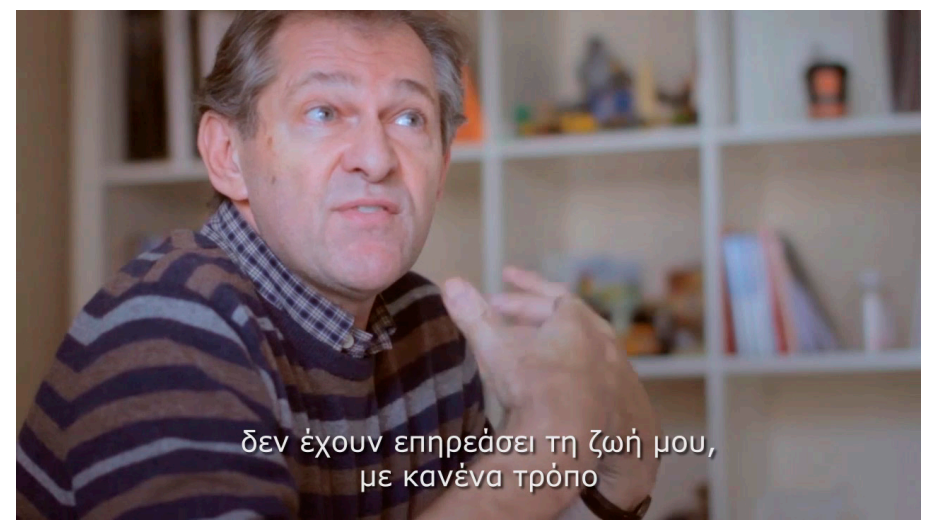

Fig. 1.

The next shot is introduced with dissolve in the titles scene, whilst the narrator is setting the main question; who could explain what are the "Jachalay"? 


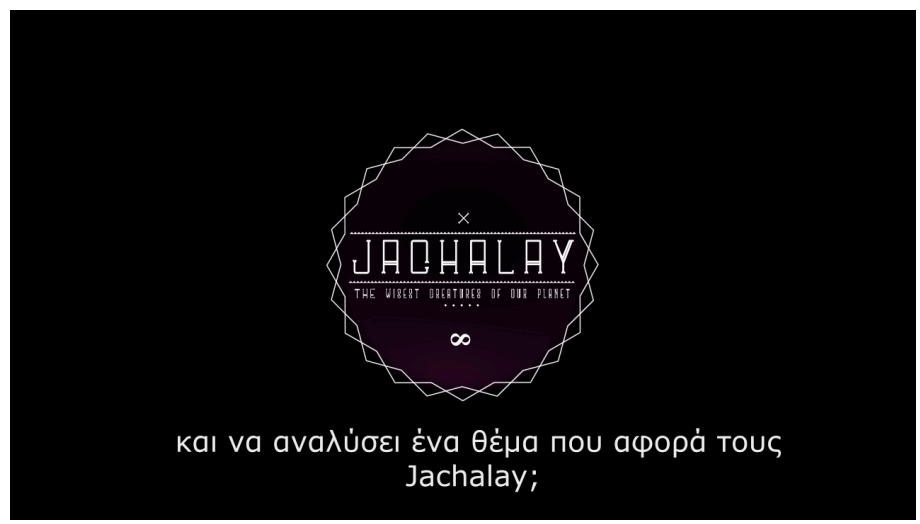

Fig. 2.

Next scene is post produced: three different European landscapes, with water as their common element, contain a "Jachalay" creature. The narrator explains there has never been any communication between humans and "Jachalays". Hence it is evident that they exist everywhere but they remain uninvolved in everything around them.

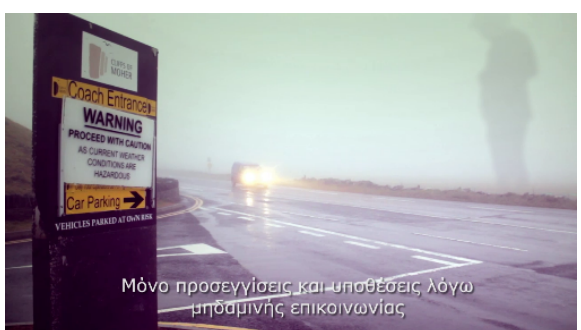

Fig. 3.

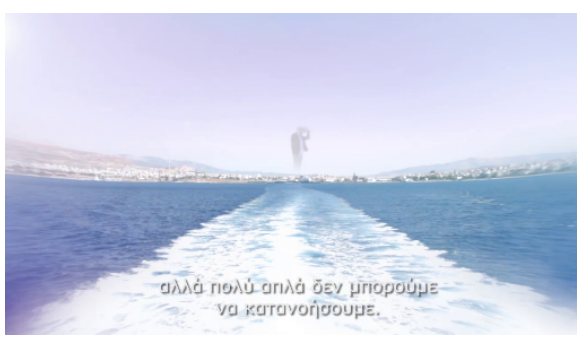

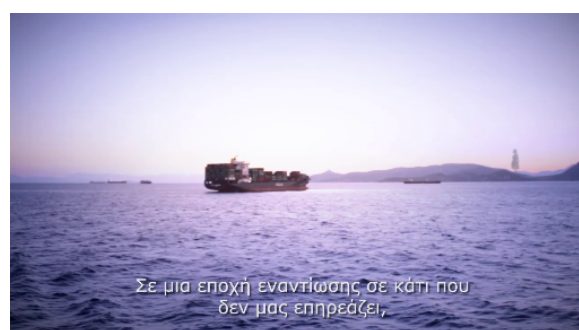

Fig. 4.

Fig. 5.

The fourth scene, an interview, is composed by five shots filmed in the Central Public Park of Athens. The shooting is medium and extreme close up where the camera is aiming a bit higher (little plongee) from the main subject. In that way the actor is transformed to a friendly character to the audience. The interviewed is a young 
Greek speaking man, a chilled out character who is claiming that all beings have a reason to exist.

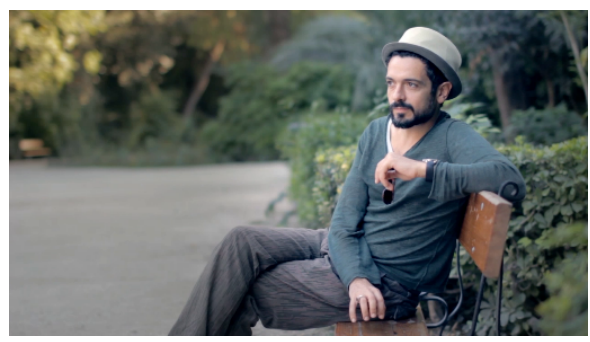

Fig. 6.

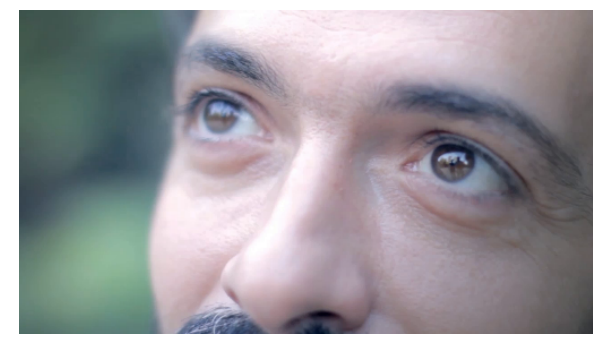

Fig. 7.

The fifth scene is a single shot, situated in North Europe where for the first time a "Jachalay" figure is moving. This suggests, that "Jachalays" are alive.

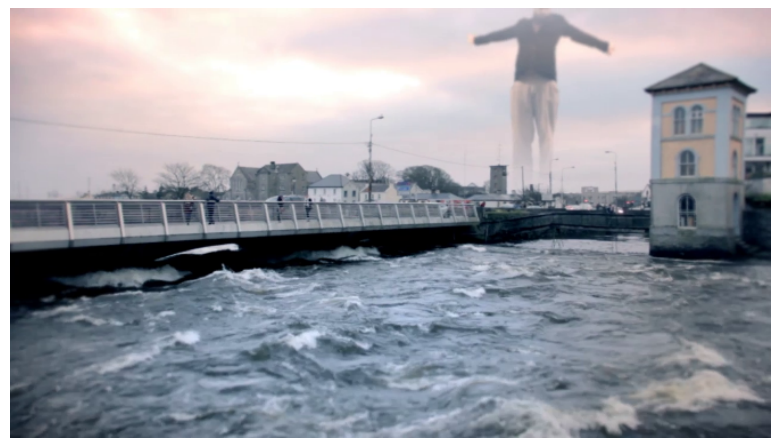

Fig. 8.

Sixth scene, an interview, situated in North Europe as well, begins with a full shot of someone stopping a middle aged lady in the street. The next five shots are close ups in order to emphasise the lady's facial expressions. She's narrating about witnessing "Jachalays" herself.

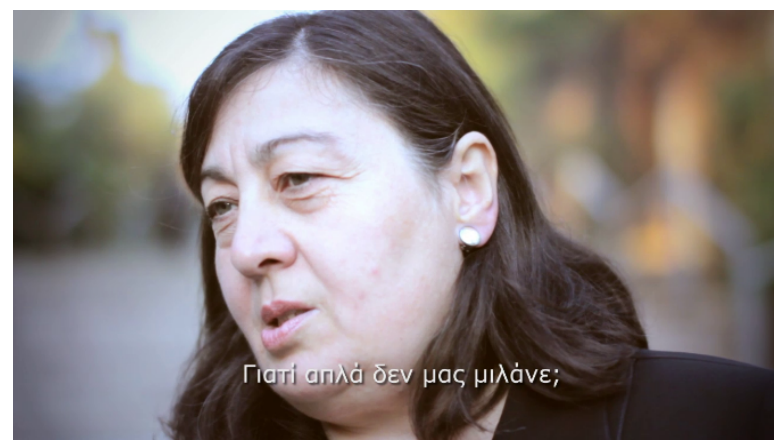

Fig. 9. 
Seventh scene is animated.

Rudolf Arnheim says: "A good image avoids pointless detail and chooses its features accurately by transmitting the important information with clarity." [4]

Following that remark, four shots presenting "medical" material, switch like an old view master in order to give the sensation of archive images. The narrator (voice off) describes that this material has been recently found, implying as well their old nature. This is also supported from the illustration's style which resembles to Leonardo Da Vinci's anatomy drawings.

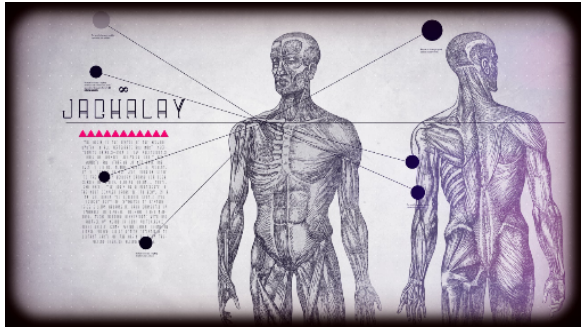

Fig. 10.

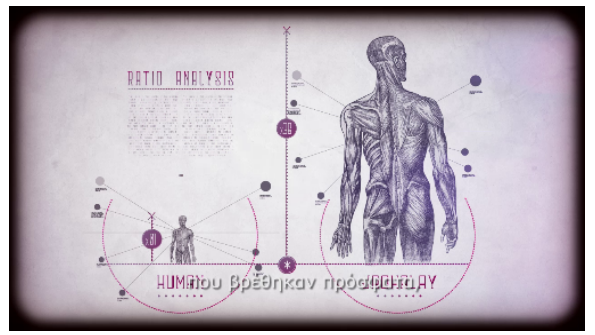

Fig. 11.

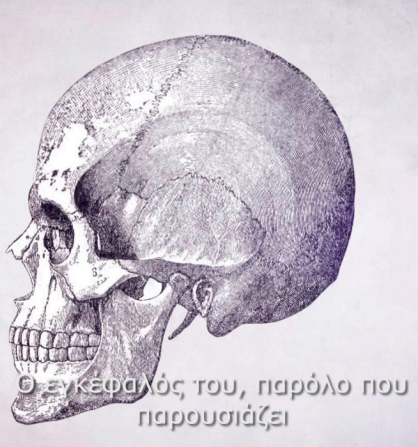

Fig. 12.

The last illustration, is a skull which dissolves and reveals a brain.

The old fashioned illustration becomes "alive" through informative animation and colour, which transfer the audience to the present. The narration reveals that the differences between a human brain and that of a "Jachalay", have been discovered. The informative animation is being enriched with additional elements which explain, the differences, visually with the use of abbreviations and descriptive text... 


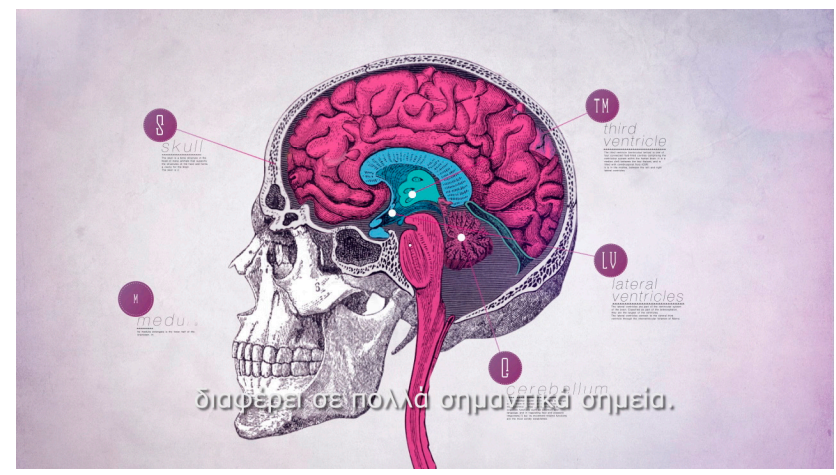

Fig. 13.

...whilst the details on what differentiates the human brain from "Jachalay"s are being fully "mentioned"...

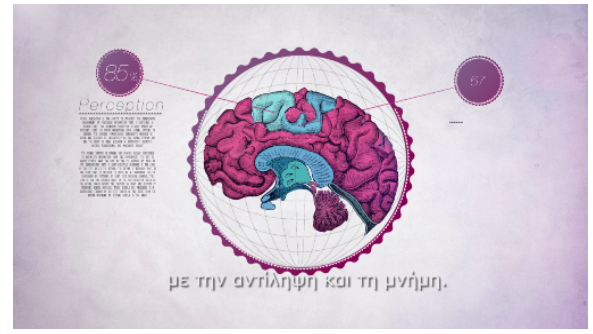

Fig. 14.

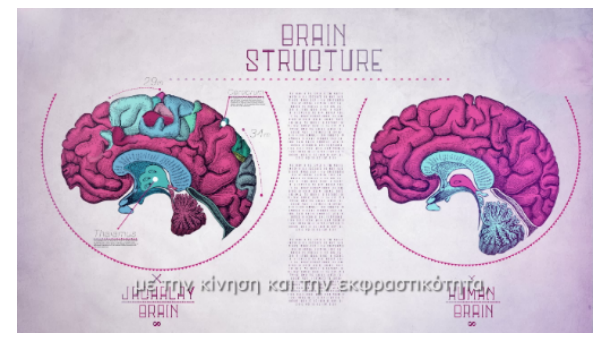

Fig. 15.

... and it gradually concludes to the two brains images so that "we can see" their differences.

The use of informative animation for the signifier, underscores validity, works like "evidence".

It describes "scientifically" the body differences by the use of medical illustrations. The comparative analysis of the two "brains", of this shot functions as a condensed conclusion. So, everything which has been previously narrated looks like scientific facts.

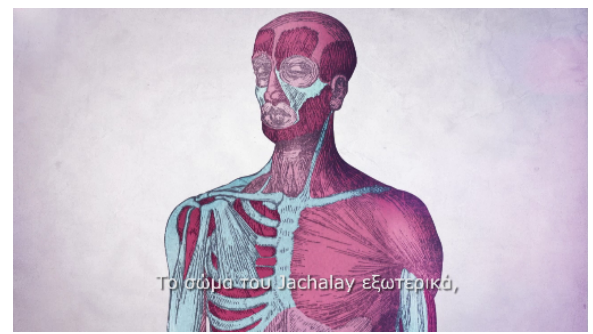

Fig. 16.

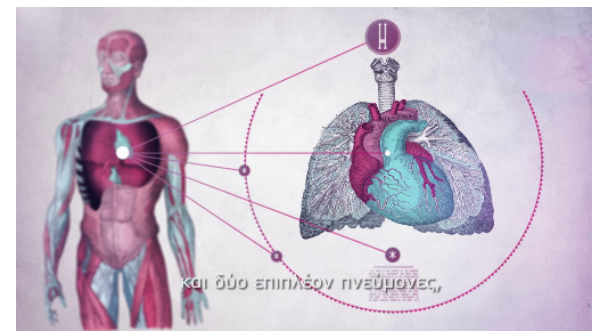

Fig. 17. 


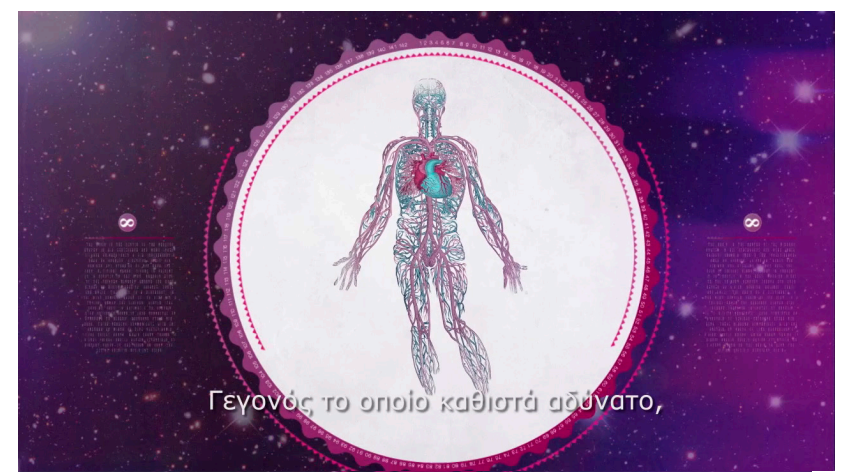

Fig. 18.

Next shot presents an illustration of Atlas. The absurd conclusion that follows this shot is that Atlas, who is lifting the World in his arms, is, perhaps... their originator!

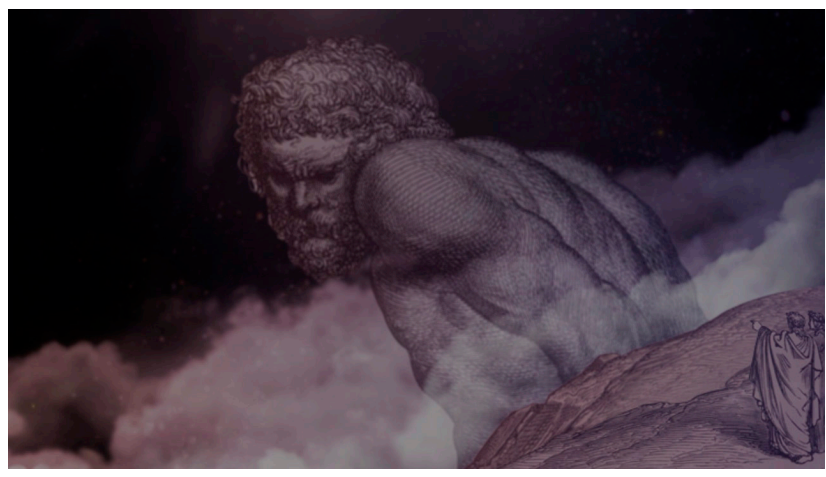

Fig.19.

Eighth scene contains digitally manipulated well known historical photos. "Jachalays" are dressed each time in a specific historical era's clothing. This choice emphasises the validity of facts.

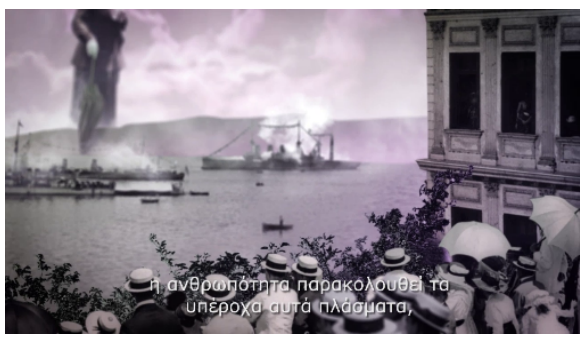

Fig. 20. End of $18^{\text {th }}$ century at the riverboats.

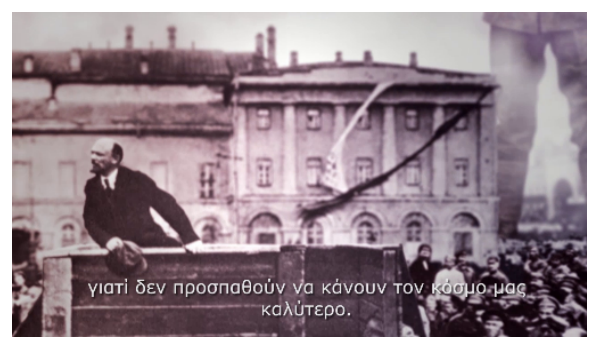

Fig. 21. Beginning of $20^{\text {th }}$ century, Russia, October revolution. 

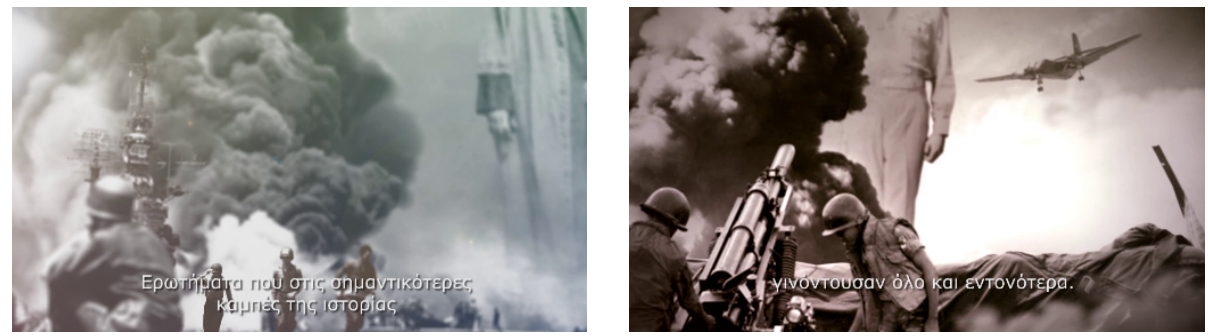

Fig. 22, 23. $2^{\text {nd }}$ World War, mid-20 ${ }^{\text {th }}$ century.

Ninth scene is composed by live shots: an old Greek man who has experienced Second World War, is describing what he "saw". He says that during bombarding in Greece, "Jachalays" were always present.

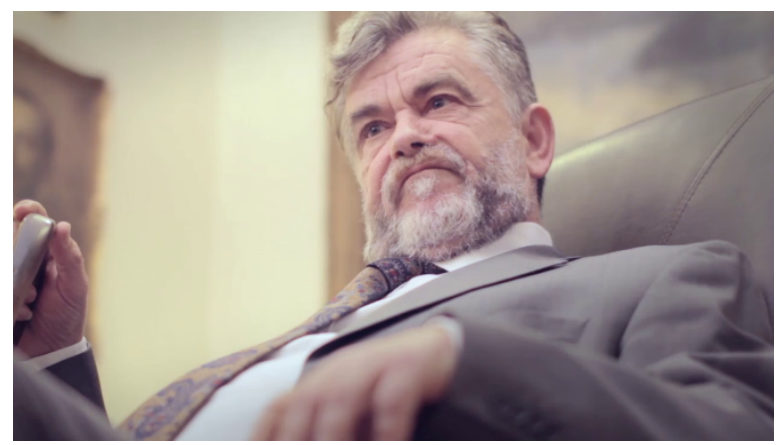

Fig. 24.

The fourth shot, is a complete reconstruction of historical photos, following the previous narrative model.

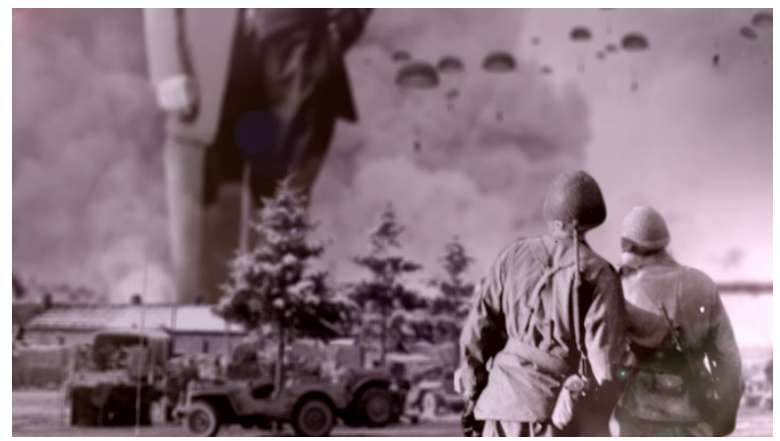

Fig. 25.

The narration continues with four close shots of the seated actor. In the fifth medium shot, he narrates whilst standing up, looking directly at the camera which is placed in a lower level than him. The camera angle implies the tension created by his words... 


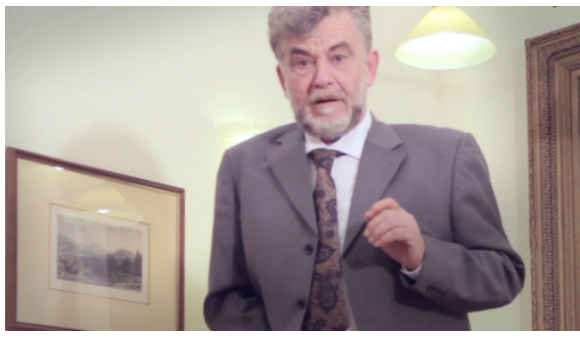

Fig. 26

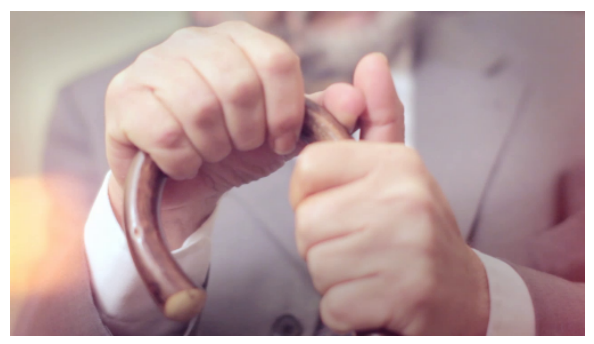

Fig. 27.

In the tenth scene, the shots are external. Through compositing the "Jachalay" figures, are placed in different landscapes.

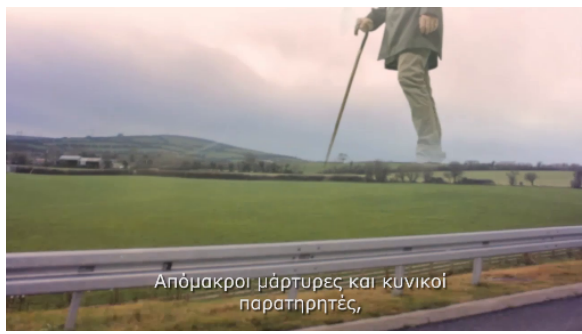

Fig. 28.

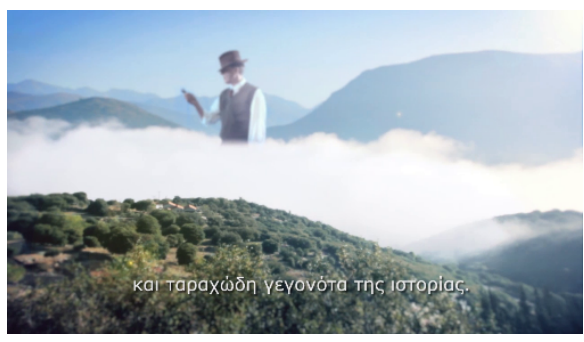

Fig. 30.

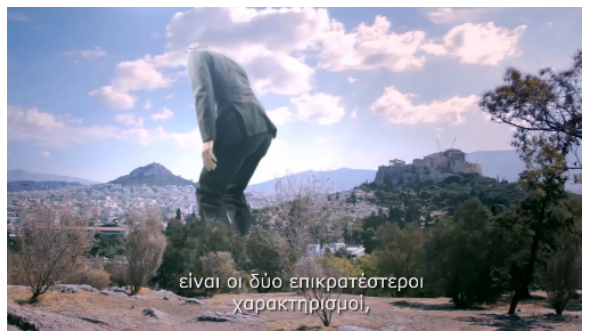

Fig. 29.

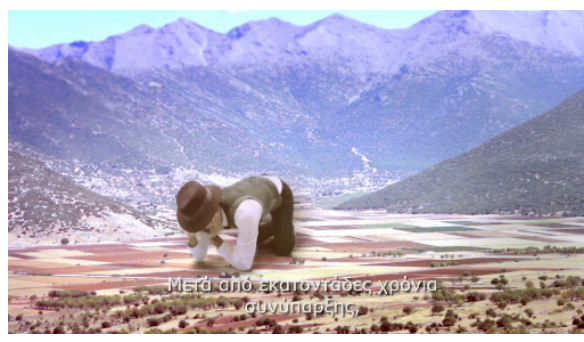

Fig. 31.

In the eleventh scene, through a time jump, the young greek man in the park while being interviewed comes to the conclusion that "Jachalays" never offered anything to the humanity. Next shots conclude all interviews with similar declarations.

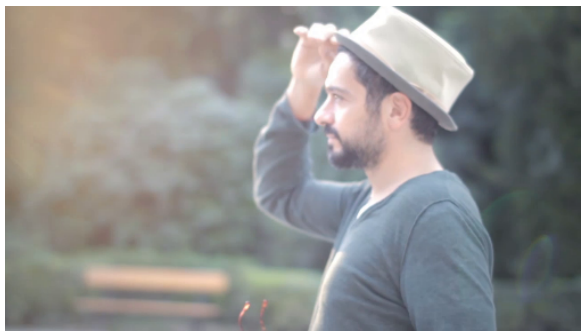

Fig. 32.

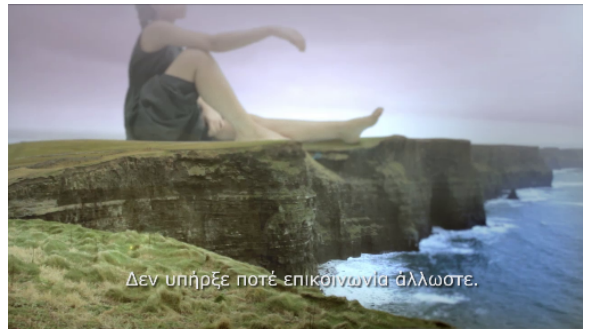

Fig. 33. 


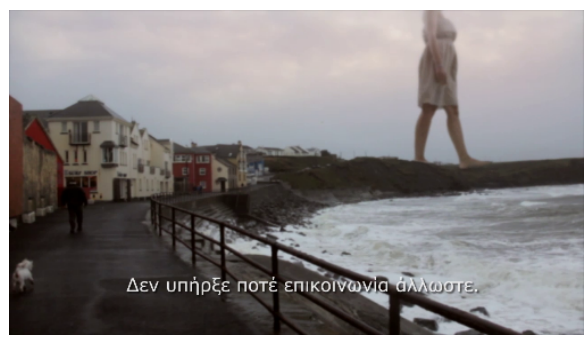

Fig. 34.

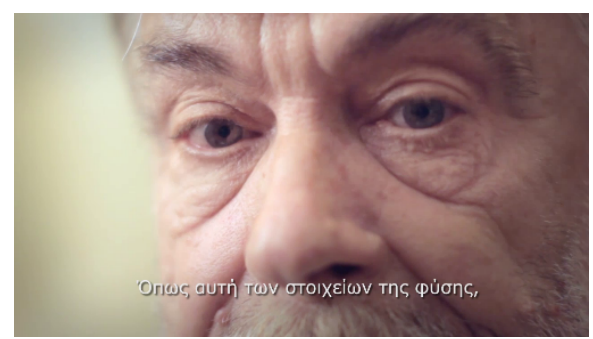

Fig. 36.

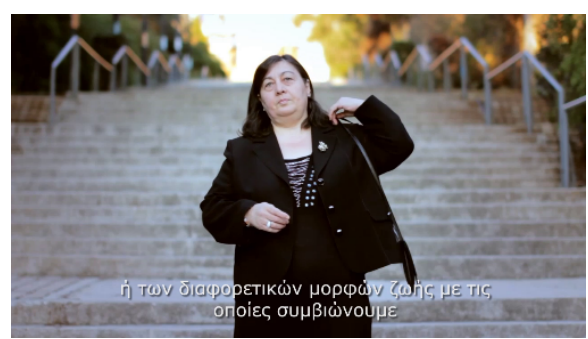

Fig. 38.

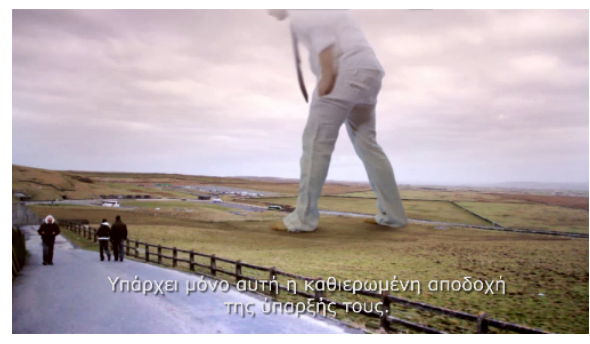

Fig. 35.

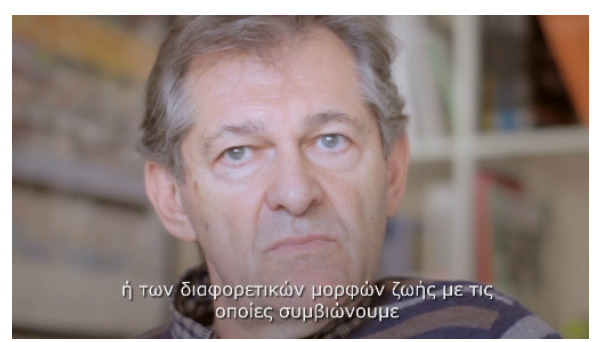

Fig. 37.

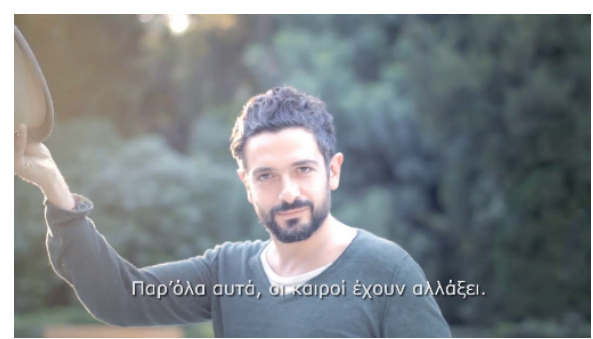

Fig. 39.

The final scene introduces a young girl as the "problem solver".

"Is there really a "why"? "Since I remember myself, they simply existed.", she says, before leaving the frame.

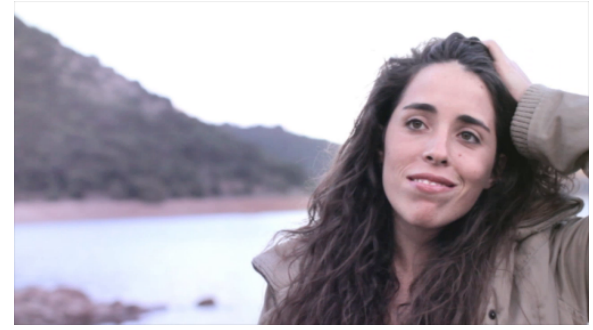

Fig. 40.

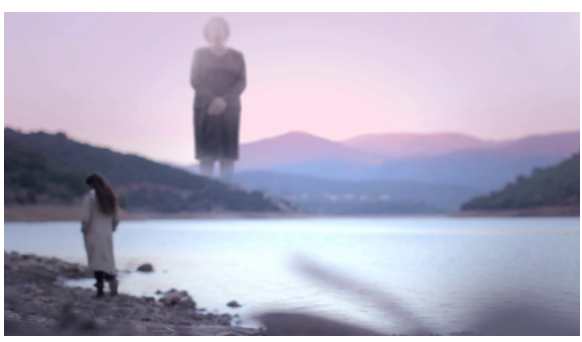

Fig. 41. 


\section{The aim of the case study film}

In "Jachalay" film, the signified is fake. It is a monckumentary movie and this is quite obvious. However several narattive techniques that the above film uses can be generally used in order to misinform.

The suggested issue is the following: When the signifier is constructed in a convincing way, the signified becomes even more convincing. Visual narratives can transmit truths as well as intentional lies in a potent way.

If the transmitted information consists of fake mixed with truth facts, it is easy for the viewer to get trapped and become victim of misinformation.

Rudolf Arnheim explains that: "The appearance of every section depends on small or big scale on the structure of the whole, and the whole, respectively, is influenced by the nature of its' sections." [4]

Therefore, if part of the work includes known elements like historical photos and scientific illustrations, then the whole work looks like real.

Through the above case study, we deal with the phenomenon of propaganda, used for hegemonic purposes. We will examine several other examples that use manipulated images, in order to misinform.

\subsection{Examples}

\section{Donald Trump's campaign}

Donald Trump during his 2016 campaign referrences to the "Intercept website". Shots of refugees in Hungary, have been used during the refugee crisis of 2015, when Syrian refugees had fled from Budapest to Austria, seeking for a passage to Germany. [5]

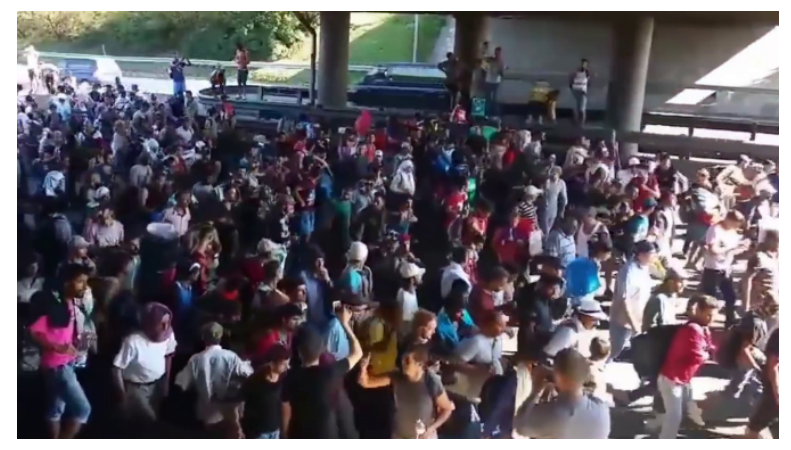

Fig. 42.

These frames were edited with his campaign video, 0.39 , presenting as the refugee hordes were crossing the borders of the USA from Mexico, making them convincing as they relate to real events happening in the USA. 
The video has been shot by a foreign reporter for New York Times. He confirmed at the website Intercept that he did not approve the use of plans in the advertisement. "Being a son of Palestinian refugees who benefited from the generosity of Jordan, a naturalized American who had been accepted to the country even after 9 September, and working as a war correspondent, the last thing I wanted was to use these shots to" dress " the Tramp's xenophobic and abhorrent message, says Nabih Boulo.[6]

\section{SIGGRAPH 2017}

\section{Synthesizing Obama: Learning Lip Sync from Audio}

In the SIGGRAPH 2017 conference, the researchers Supasorn Suwajanakorn, Steven M. Seitz and Ira Kemelmacher-Shlizermanfrom University of Washington, presented Synthesizing Obama: Learning Lip Sync from Audio [7]

Audio and visual material of Barack Obama's speeches was used. The researchers reconstructed the material in a way that an unreal conversation existed in a real time. Although the researchers used legit sound material for their study, they seamlessly reconstructed and detoured Obama's phrasing. The plethora of audio - visual material of Obama led to his selection. It proves that misinformation can happen in Media.

"Given audio of President Barack Obama, we synthesize a high quality video of him speaking with accurate lip sync, composited into a target video clip. Trained on many hours of his weekly address footage, a recurrent neural network learns the mapping from raw audio features to mouth shapes. Given the mouth shape at each time instant, we synthesize high quality mouth texture, and composite it with proper 3D pose matching to change what he appears to be saying in a target video to match the input audio track. Our approach produces photorealistic results". [8].

\section{Social media}

\section{Website Ellinika hoaxes}

The below example involves transmitting racial hate.

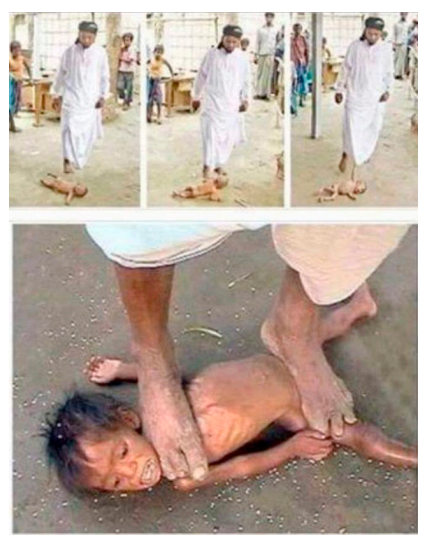

Fig. 43.

Under the title, "He was unlucky to be born by Christians in an Islamic country. They were exemplary murdered!" [9] 
It is a photo collage. The three top photos show Amzad Fakir, Bangladeshi energy therapist, who was arrested beginning of 2010 due to his method of practice.

The other photo shows another energy therapist from Indian, called Jamun Yadav, who claims to be half-god and who transmits energy to toddlers' necks through his feet.

The point is that these rough pictures are followed by a massive headlines which promote hate between two different religions.

\section{The other side of the coin}

Chantal Mouffe, in "Democratic paradox», poses the following question:

"Is it still possible for the artistic practices to play a critical role in the society where the difference between art and advertising becomes, gradually, more vague and where the artists and workers of culture have become one with the capitalistic production?"[10]

The answer is yes. The same narration and means can be used in favour of activism. The overturn of the information and art embracement with the neoliberal political theory, comes through various pathways. These practices can contribute to the questioning of the leading hegemony, by using the same means but with honesty.

\subsection{Examples}

\section{Website Beautiful Trouble}

"The Beautiful Trouble is a book, web toolbox and international network of artistactivist trainers whose mission is to make grassroots movements more creative and more effective". [11]

In the site presented an interactive info graphic all the information about theTactics, Principles, Theories, Case Studies and Practitioners of the most popular movements on the world. [12]

This is an example of world complexity communication on activism.

\section{Artistic practises}

\section{Reclaim the streets}

New artistic activism is trying to question the current consent by various means.

Respectively, the critical art foments the dispute and reveals everything that the leading consent and political correct. The artistic praxis seeks to give a voice to everyone who's being condemned by the remaining hegemony.

The new artistic activism is trying to question the current consent by various means. Civilian movements like "Reclaim the streets" [13] "Our streets are as full of capitalism as of cars and the pollution of capitalism is much more insidious" says RTS at the M41 London on $13^{\text {th }}$ July 1996. 


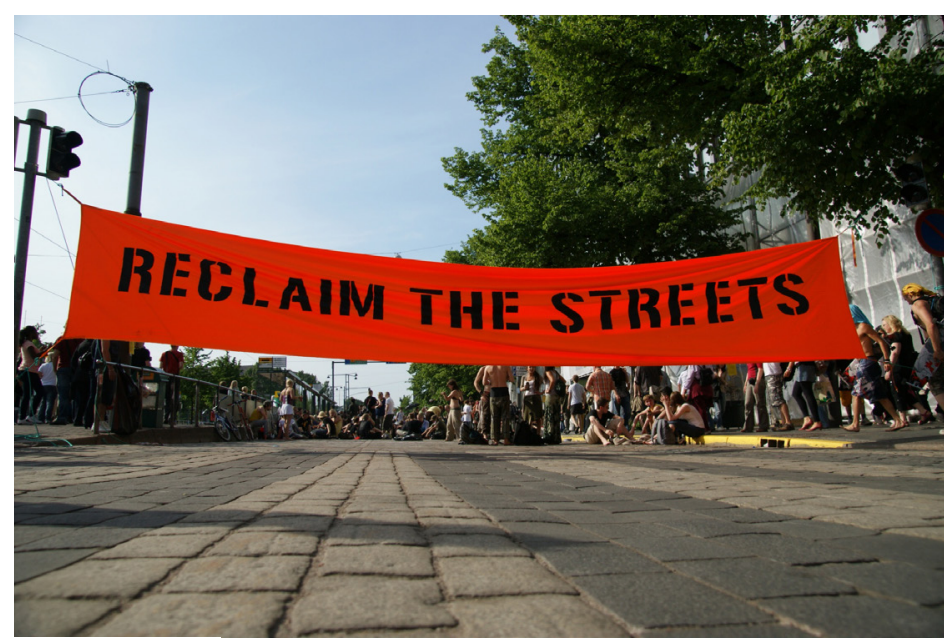

Fig. 44.

\section{Occupy Wall Street}

Another civilian movement, the Occupy Wall Street (OWS) was become as a protest movement on September 17, 2011, in Zuccotti Park, in New York City's Wall Street financial district. The central slogan "We are the 99\%" refers to the global economic inequality. At October 15, 2011 receiving global attention and spawning the movement against economic inequality worldwide as present it the info graphic. [14].

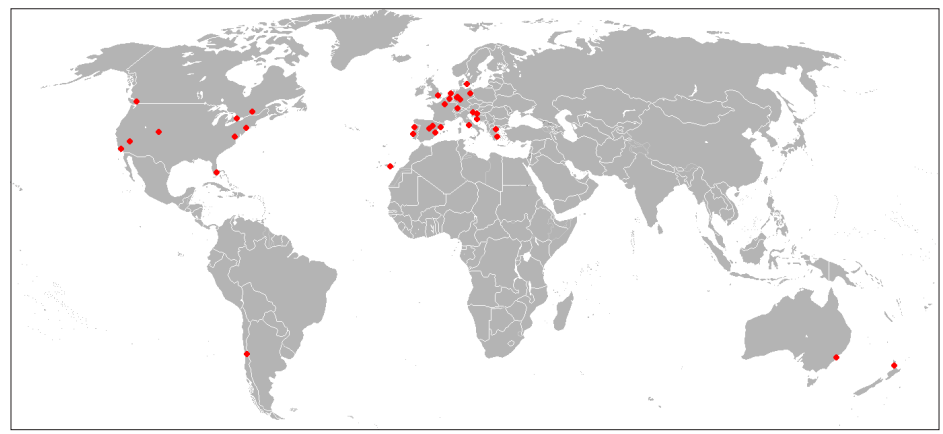

Fig. 45.

As in website [15] write, "Occupy Wall Street is a leaderless resistance movement with people of many colors, genders and political persuasions. The one thing we all have in common is that We Are The 99\% that will no longer tolerate the greed and corruption of the 1\%. We are using the revolutionary Arab Spring tactic to achieve our ends and encourage the use of nonviolence to maximize the safety of all participants". 


\section{The Yes Men}

"The Yes Men" question how to use internet and performance in "the Identity Correction". This is an example of overturning propaganda.

The commencement happened with the change in the boxes of the recorded speech of Barbie and G. I. Joe, where appealing the Media's attention was proved to be easy. This is the weapon of their political sabotage.

"We discovered people and institutions who commit terrible actions against others and we familiarized with their identities, in order to correct them. Correction of identity, instead of identity theft."

The first identity correction took place in 1999 in Bush's election campaign. After claiming the GWBush.com domain, they uploaded the "corrected ID" of the governor. On the official website Georgebush.com, the governor described himself as an ecologist, supporter of education and helper of the weak, whilst on the corrected version one could see all the information about the governor which was hidden from the average American.

Another famous correction identity is this for the website of WTO to GATT [16] (General Agreement on Tariffs and Trade). At Finland 2003, in a conference of textile industry, a "WTO spokesman" presented the future of formal work wear. [17]

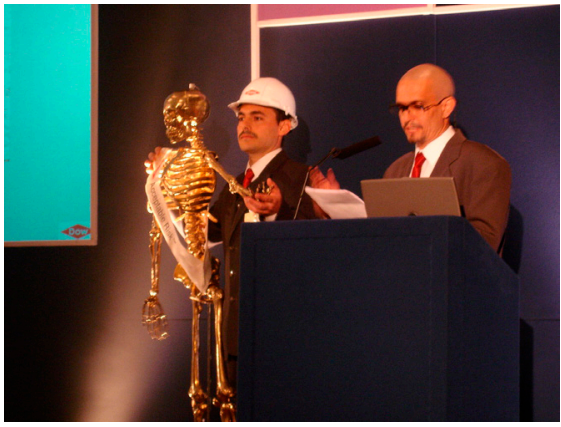

Fig. 46. Gilda, the mascot of Acceptable Risk Calculator, an idea of Dow Chemical's representative, "Erastus Hamm" 28/04/2005

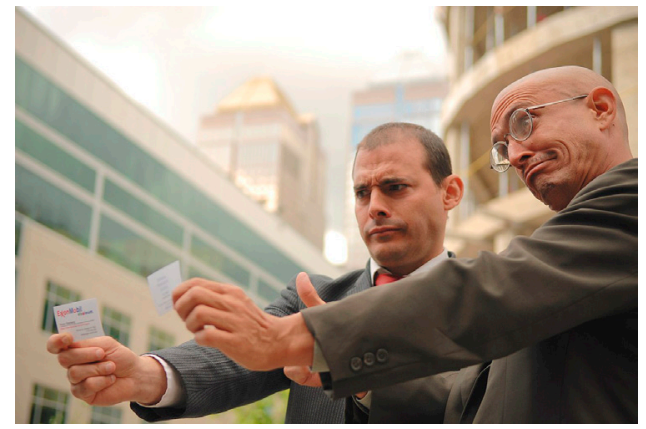

Fig. 47. Andy Bichlbaum and Mike Bonannopose as ExxonMobil executives.

Their actions can be found online on http://theyesmen.org.

The Yes Men, called "the Jonathan Swift of the Jackass Generation" by author Naomi Klein, are best known for infiltrating the world of big business and doing incredibly stupid things to expose the world's biggest corporate criminals. Although fronted by Andy Bichlbaum and Mike Bonanno, their membership includes hundreds or perhaps thousands of secret agents, all of whom were recently acquired in a hostile takeover by the Yes Lab. 
At the moment, the Yes Lab is mainly a series of brainstorms and trainings to help activist groups carry out media-getting creative actions, focused on their own campaign goals. It's a way for social justice organizations to take advantage of all that we Yes Men have learned - not only about our own ways of doing things, but those we've come in contact with over the decade and a half we've been doing this sort of thing. The Yes Lab has offices and work shopping space at NYU's Hemispheric Institute in New York. yeslab.org [18]

\section{Conclusions}

Consequently, Antonio Gramsci's "cultural hegemony" is being achieved with not only the dependence of mass media from economic factors and their involvement with politics, but and with our personal use of mass media and social media. The narcissistic "likes", benefit the pointless over-information, the projection of unimportant and extends misinformation and sciolism. The multi-level evaluation has transformed into accepting or not accepting a fact in a binary system. This results to limitation of critical thought and alienation of people's perception of the world and to the existence of spiritual leadership of the people. Therefore the user should not look for impressive images and easy text of the easily accessible information, which they forget later. The research and evaluation of information from the user themselves is a way of avoiding the phenomenon of misinformation.

Accordingly, the modern educational systems are questionable as their fundamental base of developing the critical thought is needed for a broader approach and limitation of misinformation. 


\section{References}

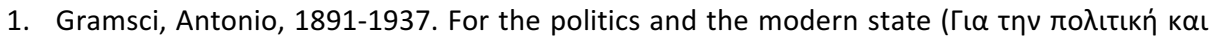
үıа то бúүxроvо кра́тоৎ) Imeresia Athens 2010

2. https://vimeo.com/153368150, https://www.behance.net/gallery/9303965/Jachalay

3. Anna Grimshaw, Amanda Ravetz. Observational Cinema: Anthropology, Film and the Ex-

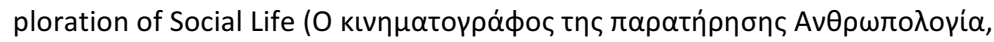

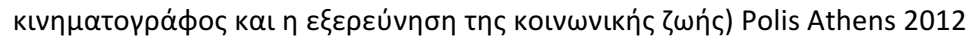

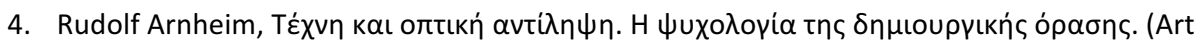
and visual perception, a psychology of creative eye), University of California Press, 1974. Themelio, Athens 2005

5. https://www.youtube.com/watch?time_continue=2\&v=vST61W4bGm8

6. EvageliaBifi article $06 / 11 / 2016$, To Vima (To $\beta$ ń $\mu \alpha$ ) newspaper http://www.tovima.gr/world/article/?aid=842417

7. SIGGRAPH 2017 Full Video: https://www.youtube.com/watch?v=MVBe6_o4cMI

8. https://grail.cs.washington.edu/projects/AudioToObama/siggraph17_obama.pdf

9. http://ellinikahoaxes.gr/2016/03/23/facebook-foto-xristianoi-islam/

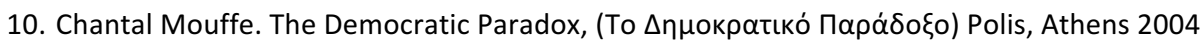

11. http://beautifultrouble.org/

12. http://explore.beautifultrouble.org/\#-1:01110

13. http://rts.gn.apc.org/

14. https://en.wikipedia.org/wiki/15_October_2011_global_protests

15. http://occupywallst.org/

16. https://www.wto.org/ to http://www.gatt.org/

17. $h t t p s: / / w w w . y o u t u b e . c o m / w a t c h ? v=G E u z V M w s K 7 o$

18. http://beautifultrouble.org/practitioner/yes-men/ 